\title{
Classification of Willow Species Using Large-Scale Aerial Photography
}

\author{
Steven L. Petersen, ${ }^{1}$ Tamzen K. Stringham, ${ }^{2}$ \\ and Andrea S. Laliberte ${ }^{3}$
}

\begin{abstract}
Authors are ${ }^{1}$ Assistant Professor, Department of Rangeland Ecology and Management, Oregon State University, Corvallis, OR 97331; ${ }^{2}$ Assistant Professor, Department of Rangeland Ecology and Management, Oregon State University, Corvallis, OR 97331; and ${ }^{3}$ Research Scientist, ARS Jornada Experimental Range, New Mexico State University, Las Cruces, NM 88003.
\end{abstract}

\begin{abstract}
The distribution characteristics of willow (genus Salix) can be evaluated with the use of remote sensing, geographic information systems (GIS) technologies, and spatial analysis. This information can be used to better understand willow ecology, such as willow community composition, species relationships, and associations with other landscape attributes (i.e., soils, elevation gradients, water sources, and landscape position). Aerial photographs of a willow-dominated riparian area located in southeastern Oregon were taken in November 1999 at a 1:2 400 scale. Four basic techniques were used to separate willow species from each other in both color and infrared images using ERDAS Imagine ${ }^{\circledR}$ GIS. Willow species included Geyers willow (Salix geyeriana Anderson), Booth willow (Salix boothii Dorn), and Lemmon's willow (Salix lemmonii Bebb). The techniques used to analyze aerial photographs included image resampling (degrade), image filtering (smoothing), unsupervised classification, and supervised classification. Highest accuracy was obtained using a supervised classification of the color images smoothed with a low-pass convolution filter (84.6\% accuracy). Spectral samples were collected using a polygon digitizing method, which had superior results compared to the seed or region growing method. The infrared image was least effective in separating the plants into species classes $(58.6 \%$ accuracy). This may be due to the lack of the blue band in the infrared image.
\end{abstract}

\section{Resumen}

Las características de distribución del "Willow" (genero Salix) pueden ser evaluadas con el uso de sensores remotos, tecnologías de sistemas de información geográfica (GIS) y análisis espacial. Esta información puede ser usada para entender mejor la ecología del "Willow," por ejemplo, la composición de las comunidades de esta especie, relaciones de especies y asociaciones con otros atributos del paisaje (por ejemplo, suelos, gradientes de elevación, fuentes de agua y posición del paisaje. En un área ribereña del sudeste de Oregon dominada por "Willow," se tomaron fotografías aéreas en Noviembre de 1999 en una escala de 1:2 400. Se utilizaron cuatro técnicas básicas para separar las especies de "Willow" de las otras especies, tanto en fotografías a color como infrarrojas, usando ERDAS Imagine ${ }^{\circledR}$ GIS. Las especies de "Willow" incluidas fueron "Geyers willow" (Salix geyeriana Anderson), "Booth willow" (Salix boothii Dorn), y "Lemmon's willow” (Salix lemmonii Bebb). Las técnicas usadas para analizar las fotografías aéreas incluyeron el remuestreo de imagen (degrado), filtración de imagen (suavizado), clasificación no supervisada y clasificación supervisada. La mayor exactitud se obtuvo usando una clasificación supervisada de las imágenes a color suavizadas con un filtro convolución de paso bajo (84.6\% exactitud). Las muestras espectrales fueron colectadas usado el método de digitalización del polígono, el cual tuvo resultados superiores a los obtenidos con el método de semilla o región creciente. La imagen infrarroja fue la menos efectiva para separar las plantas en clases de especies (58.6\% exactitud), esto puede ser debido a la falta de la banda azul en la imagen infrarroja.

Key Words: ecology, remote sensing, Salix, GIS, ERDAS Imagine

\section{INTRODUCTION}

Willows are a diverse group of plants found in almost every part of the world (Newsholme 1992). They serve several important ecological roles, in particular establishing and maintaining riparian zone stability and biological diversity (Kovalchik and Elmore 1992). Willows provide important

At the time of the research, the senior author was a PhD graduate student, Dept of Rangeland Resources, Oregon State University, Corvallis, OR 97331.

Correspondence: Dr Steven L. Petersen, Dept of Rangeland Ecology and Management, 202 Strand Agricultural Hall, Oregon State University, Corvallis, OR 97331.

Manuscript received 15 September 2004; manuscript accepted 3 August 2005. habitat and forage for a variety of bird, mammal, fish, and insect species (Shulz and Leininger 1990; Newsholme 1992; Knopf and Stanley 2002). Willows stabilize stream channel banks with an extensive subsurface spreading root system and dissipate flood energy with submerged branches (Brunsfeld and Johnson 1985). They filter debris and trap suspended sediments (Kovalchik and Elmore 1992). Methods that can be utilized to accurately classify willow species can be used by land managers and scientists as an affordable, time-efficient mechanism for monitoring willow communities.

The ability to describe the distribution of plants on the landscape has steadily improved with the advancement of remote sensing and GIS technology. Large-scale aerial photography provides a wealth of information that can be used to 
classify plant communities and predict community composition (Tueller 1996). High-resolution data can facilitate the description and interpretation of specific photographic parameters (Golden et al. 1996; Warner et al. 1996) including plant distribution patterns. Tueller et al. (1988) used aerial photography to assess vegetation composition and to detect change in shrub cover. Meyer et al. (1996) were able to differentiate individual tree species using high-resolution aerial photographs with $80 \%$ accuracy. Martin et al. (1998) distinguished deciduous, coniferous and mixed forest stands using high spectral resolution data, but found that separating individual tree species was difficult.

In digital image processing, both reflectance characteristics and plant surface texture can be useful in plant classification and reducing clustering error (Sali and Wolfson 1992; Wulder et al. 1998). Species classification using remotely sensed imagery has been developed using primarily aerial photography. Satellite imagery tends to have low spectral resolution and greater atmospheric scattering (i.e., Rayleigh or Mie), making species separation difficult; however, increased satellite resolution (i.e., $1 \mathrm{~m}$ resolution in Ikonos and Quickbird) can lead to higher species separation capabilities (Lillesand and Kiefer 2000).

The purpose of this study is to classify 3 willow species using color and color infrared photography and to assess different digital image processing and classification techniques to reduce pixel variability and minimize the effects of shadow on classification accuracy.

\section{MATERIALS AND METHODS}

\section{Study Site Description}

The study area is located within the headwater reach of a streamside riparian corridor in a mountain big sagebrush (Artemesia tridentata var. vaseyana Hook.)-dominated ecosystem in the Steens Mountain area of southeastern Oregon (UTM $357,500.00 \mathrm{E}, 4,700,000.00 \mathrm{~N})$. The climate of the study area consists of hot, dry summers and cold winters. In July to August, temperatures often exceed $35^{\circ} \mathrm{C}$, with few short-duration rainfall events. Most precipitation occurs during the winter months from frequent snowstorms. Total annual average precipitation for the area is approximately $350 \mathrm{~mm}$. The site, located at 1990-2 $010 \mathrm{~m}$ elevation, was selected because of the high density and cover of willow species along the riparian corridor. The riparian corridor occurring within the study area is approximately $525 \mathrm{~m}$ long. Species included in the study were Geyers willow (Salix geyeriana Anderson), Booth willow (Salix boothii Dorn), and Lemmon's willow (Salix lemmonii Bebb).

\section{Species Description}

S. boothii is a rounded shrub, 3 to $6 \mathrm{~m}$ tall, with numerous basal stems generally more than $5 \mathrm{~cm}$ in diameter. Leaves are thick and green on each side. It is one of the most common willows on Steens Mountain, ranging from sagebrush valley bottoms above $2100 \mathrm{~m}$ to low subalpine forests below 2440 m elevation (Brunsfeld and Johnson 1985; Mansfield 2000). It is able to occupy a wide range of soil types and moisture regimes, usually near streams and seeps. Plants are dioceous, with maximum seed production occurring between ages 2 and 10 years. Stem senescence occurs between 15 and 20 years.
S. geyeriana is a 2- to 5-m-tall deciduous shrub with numerous slender, straight, and erect stems that form a tight basal cluster (Brunsfeld and Johnson 1985). The relatively narrow leaf blades are silvery or gray-green above and pale green beneath, caused by a glaucous surface visible through dense pubescence. It is generally located in riparian woodlands and near springs below $2000 \mathrm{~m}$ in deep, fine-textured soils of alluvial origin (Mansfield 2000). It grows well in a wide range of moisture conditions but rarely in places where groundwater is deeper than $1 \mathrm{~m}$. Unlike $S$. boothii, S. geyeriana is often more abundant in drier sites (Brunsfeld and Johnson 1985). Plants have highest seed production between ages 2 and 10 .

S. lemmonii is a 2- to 4-m-tall deciduous shrub with numerous slender, crooked stems that form a loose basal cluster. Leaves are green and shiny above and pale glaucous below with a finely pubescent surface on both sides. It is typically found near streams, ponds, lakes, and wet meadows between 1800 and $2400 \mathrm{~m}$. It also is one of the most common willow species growing in subalpine riparian areas on Steens Mountain (Mansfield 2000) and, like Geyers willow, can grow on drier potions of the riparian zone (Brunsfeld and Johnson 1985).

\section{Image Procurement and Processing}

A series of 1:2 400 scale color and color-infrared aerial photographs were taken of the study site on 29 September 1999 using a large-format $(22.9 \times 22.9 \mathrm{~cm})$ mapping camera with a $305.22-\mathrm{mm}$ focal length and $24-\mathrm{cm}$ film. Prints were scanned at 600-dpi resolution, saved in a 24-bit tagged image file format, and imported into the digital image processing program ERDAS Imagine ${ }^{\circledR}$ (ERDAS Inc. 1997) for image analysis. Approximate pixel size (in the field) of scanned images was $7 \times 7 \mathrm{~cm}$.

During the summer of 2001, each willow plant growing within the study area was identified and mapped using the aerial photographs for locating each individual plant and delineating plant canopy cover. This information was used for developing the spectral signature library for image classification and for assessing classification accuracy. To reduce the file size of each scanned image and concentrate image analysis to the plant species of interest, the riparian area was clipped from the surrounding sagebrush steppe community.

To determine which image processing technique was most effective in identifying individual willow species, several image processing methods were investigated. These techniques were divided into 4 basic categories: image resampling, convolution filtering, unsupervised classification, and supervised classification. Image resampling consisted of reducing image pixel size from $7 \times 7 \mathrm{~cm}$ to $4 \times 4 \mathrm{~m}$ using a mean filter. This type of image degradation was intended to reduce the spectral variability between pixels occurring within the canopy area for each plant. Filtering methods were used to reduce pixel spectral variability of individuals of the same plant species without losing spatial image resolution. These included the use of mean, median, and convolution low-pass filters. These filters functioned in smoothing the image with the intention of increasing classification accuracy. The convolution filter functions by averaging small sets of pixels across an image, resulting in a change in the spatial frequency characteristics of the image (ERDAS 1997). Different filter kernel sizes (number of pixels) were also compared to 
Table 1. Overall classification accuracy and kappa statistic for each image processing and analysis method evaluated.

\begin{tabular}{lcc}
\hline Classification method & Overall accuracy & Kappa statistic \\
\hline Color degrade & 67.4 & 0.587 \\
Color unsupervised & 75.0 & 0.671 \\
Color supervised-seed & 76.6 & 0.703 \\
Color supervised-polygon & 84.6 & 0.793 \\
Infrared supervised & 58.6 & 0.492 \\
\hline
\end{tabular}

determine if increasing window size would result in more effective image smoothing and species separation. Kernel sizes used in filtering were $3 \times 3,5 \times 5$, and $7 \times 7$ applied to the same image once and $7 \times 7$ applied to the same image twice.

\section{Image Classification}

An unsupervised classification was performed on the original, degraded, and filtered color and color-infrared images. From each image, 30 initial clusters were generated using the Iterative Self-Organizing Data Analysis Technique (ISODATA) (Lowell and Jaton 1999). These clusters were then consolidated to form each species class, a shadow class, and a class consisting of bare ground and sagebrush cover for a total of 5 classes. Two methods were used to collect training samples for the supervised classification. The "seed" (region growing) method generated training samples by incorporating adjacent pixels with similar spectral characteristics into a single sample. The "polygon" method generated each sample by digitizing a polygon around the plant canopy (or canopy of more than one plant when plants of the same species occurred adjacent to each other because of their multistem nature) as well as the soil, shrub, and grass cover type, capturing the range of variability in that sample. Approximately 20 training samples were collected for each species, shadow, and other surface features (grass, shrubs, and aspen) prior to classification. In case a class was poorly identified, additional samples were obtained for that species, resulting in a "fine-tuning" of the classification for that class.

\section{Accuracy Assessment}

The accuracy in separating willow species within each image was assessed by comparing the ground-truthed maps of willow species as previously described with the classified image using an accuracy assessment. The accuracy assessment was completed using 500 computer-generated stratified random points (individual pixels) with a minimum of 40 random points assigned to the smallest class. The pixel value for each random point was compared with the plant species and canopy cover map produced and verified in the field (see Image Procurement and Processing). Potential error in accurately identifying each random point could occur at the interface between 2 different plant species (because of the high resolution of the image). However, points generally occurred clearly within the bounds of each cover type.

In this assessment, total overall classification accuracy, species-level producers and users accuracy, and the overall kappa statistic were generated. Producers accuracy is computed by dividing the number of correctly classified pixels (along the main matrix diagonal) assigned to a category by the total number of reference pixels that were classified in that category (error of omission). This measure indicates the degree to which the reference data have been accurately mapped. Users accuracy is computed by dividing the number of correctly classified pixels in each category by the total number of pixels that were classified in that category (error of commission). It indicates the probability (reliability) that a pixel assigned into a particular category actually represents that category (cover type) on the ground (Congalton 1991). Together, these measures indicate the reliability of the classified image to represent the actual cover types observed in the field. The kappa statistic expresses the proportionate reduction in error resulting from the classification procedure compared to a completely random classification (Lowell and Jaton 1999).

\section{RESULTS}

The purpose of this study was to determine if Geyers, Booth, and yellow willow plants can be distinguished from each other using high-resolution remotely sensed imagery. Several filtering and classification methods were investigated to determine which approach is most effective in accurately separating each of the 3 species. The supervised classification of the filtered color image $(7 \times 7$ convolution filter applied twice) produced a higher species separation accuracy compared to the original image (Table 1). The highest accuracy was obtained using the polygon method with an accuracy of $82.0 \%$ (kappa $=0.772$; Fig. 1a). Identifying training samples with the seed method resulted in $76.6 \%$ classification accuracy $($ kappa $=0.703)$. Variability in pixel values was significantly reduced in comparison to the unfiltered image, with most confusion occurring primarily along the edges of willow and bare ground or shadow.

The unsupervised classification of the original color image generated weak species classes noted by the high amount of variability in pixel values resulting from confusion between species (Fig. 1b) compared to the supervised classification of the same image (Fig. 1c). In particular, S. lemmonii was confused with $S$. boothii (Table 2). After image smoothing with a $7 \times 7$ convolution filter applied twice, the confusion between species was greatly reduced, and species classification accuracy improved $(75 \%$ accuracy, kappa $=0.671$; Fig. $1 \mathrm{c})$.

Resampling the image to a larger pixel size resulted in low classification accuracy $(67.4 \%$, kappa $=0.587)$ using a supervised classification (Table 1). It appeared that the boundary between classes could not be delineated as well with image resampling as it could be with smoothing techniques. Several smoothing methods were used, including the mean, median, and maximum filters; however, the highest accuracy for both color and infrared was obtained with the convolution filter. Also, accuracy was improved using larger kernel sizes $(7 \times 7$ window). Since accuracy was greatest with a low-pass convolution filter applied within a $7 \times 7$ window twice, the remaining classification techniques were analyzed using this same filtering method. The supervised classification of the processed color infrared imagery produced the poorest species classification $(58.6 \%$, kappa $=0.492$; Fig. 1d). Error associated with shadow was reduced with the use of the convolution filter, in particular using the polygon supervised classification method of the color image (95.1\% producers accuracy; Table 2 ). 

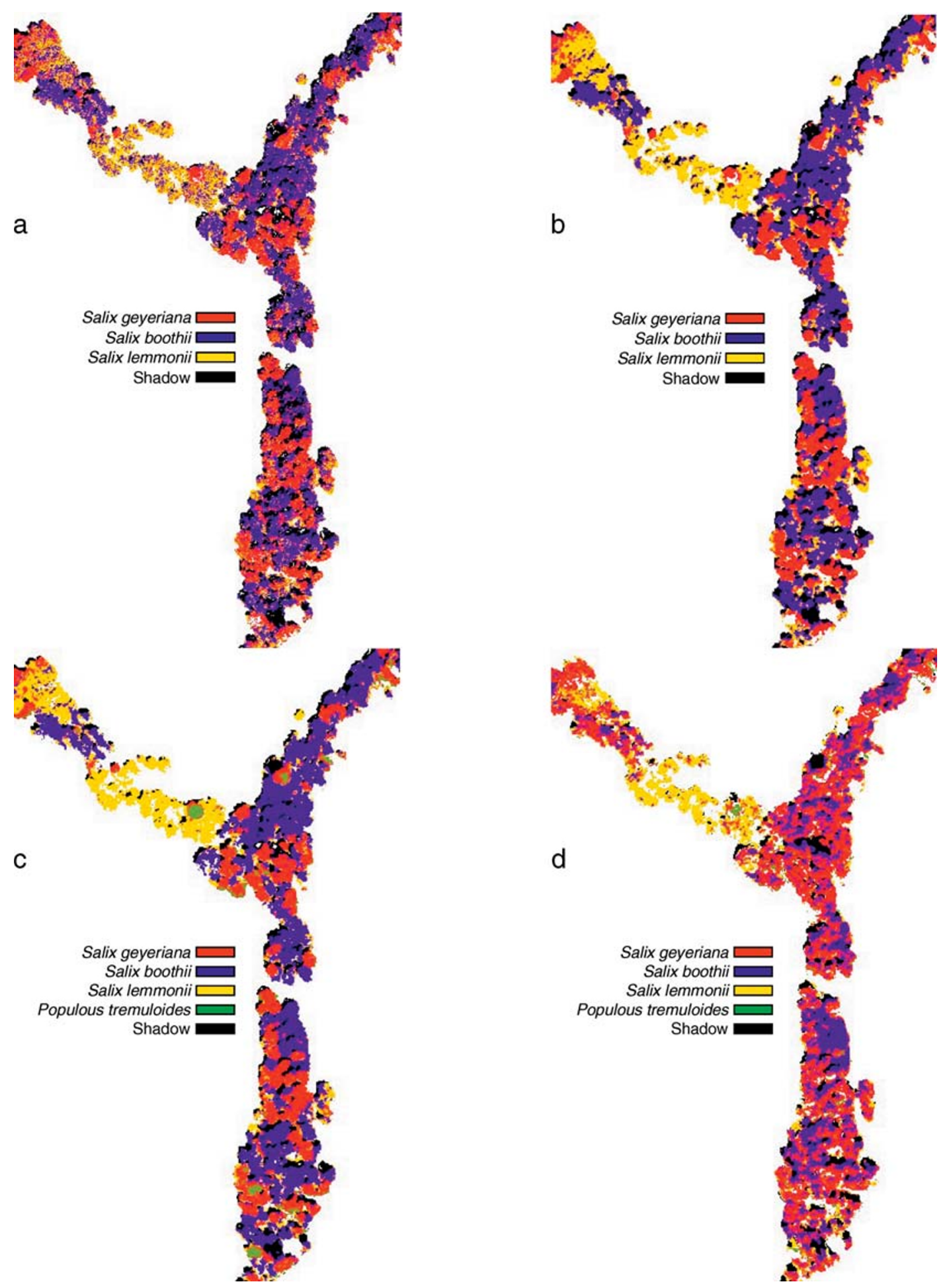

Figure 1. Classes generated using image analysis techniques. a, supervised classification of the color image, filtered with a low-pass $7 \times 7$ kernel convolution filter applied twice. $\mathbf{b}$, unsupervised classification of the original color image. c, unsupervised classification of the original image, filtered with a low-pass $7 \times 7$ kernel convolution filter applied twice. d, supervised classification of the infrared image, filtered with a low-pass $7 \times 7$ kernel convolution filter applied twice.

Total cover of each willow species, shadow, and soil and shrub cover was calculated from each image included in the analysis (Table 3). Based on the supervised classification of the color image using the polygon classification technique, which was found to have high classification accuracy, S. boothii had the greatest cover of all species present $(39 \%)$, S. geyeriana had $21 \%$ cover, and
S. lemmonii had $19 \%$ cover. Shadow cover was also lower in this image $(12 \%)$ compared to other classification methods except the supervised-seed method, which had $8 \%$ cover.

Fine-tuning the classification by incorporating additional training samples was particularly useful in eliminating the error associated with shadow, which causes the misallocation of plant 
Table 2. Results of the accuracy assessment performed for willow species, shadow, and ground cover in relation to image resampling (degrade), filtering, and/or image classification (supervised and unsupervised).

\begin{tabular}{|c|c|c|c|c|c|c|c|c|c|c|c|c|c|c|c|}
\hline \multirow[b]{2}{*}{ Species } & \multicolumn{3}{|c|}{ Color degrade } & \multicolumn{3}{|c|}{ Color unsupervised } & \multicolumn{3}{|c|}{ Color supervised—seed } & \multicolumn{3}{|c|}{ Color supervised—polygon } & \multicolumn{3}{|c|}{ Infrared supervised-polygon } \\
\hline & Prod & User & Kappa & Prod & User & Kappa & Prod & User & Kappa & Prod & User & Kappa & Prod & User & Kappa \\
\hline Salix geyerianna & 75.8 & 77.3 & 0.717 & 82.5 & 72.1 & 0.654 & 73.5 & 80.6 & 0.794 & 82.2 & 84.7 & 0.808 & 60.2 & 39.4 & 0.256 \\
\hline Salix Iemmonii & 65.5 & 37.6 & 0.294 & 76.4 & 53.4 & 0.456 & 62.2 & 67.1 & 0.607 & 84.7 & 67.8 & 0.624 & 54.4 & 63.2 & 0.563 \\
\hline Shadow & 86.8 & 54.1 & 0.503 & 98.1 & 66.2 & 0.623 & 90.2 & 94.8 & 0.503 & 78.6 & 63.5 & 0.601 & 94.2 & 66.2 & 0.623 \\
\hline Bare/grass & 39.7 & 61.7 & 0.552 & 65.3 & 80.0 & 0.778 & 69.8 & 54.6 & 0.941 & 100.0 & 92.8 & 0.917 & 64.6 & 65.4 & 0.589 \\
\hline
\end{tabular}

cover pixels to the shadow class, resulting in lower plant cover values for the classified image compared to actual plant cover.

\section{DISCUSSION AND CONCLUSION}

Of the techniques investigated, resampling (degrading) the image actually created greater confusion between the spectral classes since it decreased resolution near the edge of each feature. Accuracy was slightly improved with a $3 \times 3$ kernel size since pixels were numerous within the canopy of each feature. As window size was increased, classification accuracy improved up to a $7 \times 7$ window applied to the same image twice. Stuckens et al. (2000) suggest that large kernels are most appropriate for large-scale imagery or large land cover entities because of high image resolution; however, $3 \times 3$ kernels are the most widely used window size in image interpretation. Mean, median, and minimum filters were less effective than the convolution filter in producing a smoothed image that produced the highest classification accuracy.

Infrared images were in every case less effective in generating accurate species classes than color images. A possible explanation for this is the absence of the blue band in the infrared images. In high-level aerial photography and satellite imagery, the quality of the blue band is lost because of atmospheric interference referred to as Raleigh scatter (Lillesand and Kiefer 2000). Since these images were taken relatively close to the ground where the scattering of blue light was minimal, the blue band maintained the high level of data quality and may have provided valuable information used in accurately separating willow species. This assumption is supported by results reported by Harris et al. (1996). They found that a Normalized Difference Vegetation Index based on the blue band was more useful in separating vegetation into classes than one based on the red band.

Comparing classification techniques, the supervised classification method was generally superior to unsupervised classifi- cation in separating species cover classes. For the supervised classification, the collection of training samples by digitizing around each willow species was more effective than using the seed pixel (region growing) method, presumably because plants, shadow, and ground cover could be outlined more precisely. An increased distinction between different classes made it possible to average the pixels within the entire plant crown rather than only a portion of the plant, such as with the seed pixel method. The size of the shadow class was also reduced using the polygon method since a greater proportion of the gradient between shadow and the plant creating the shadow could be included within that species class.

Within the study site area, S. boothii had the highest plant cover, more than 2 times greater than $S$. geyeriana and $S$. lemmonii. S. boothii and S. geyeriana occurred intermixed in the riparian woodland, whereas $S$. lemmonii occurred primarily in isolated sections along the riparian zone. Conversely, the distribution pattern may provide insight into soil type, channel materials, and moisture regimes.

\section{MANAGEMENT IMPLICATIONS}

The techniques developed from this study may be utilized to build a database of willow species distribution along elevation gradients, channel types, soil series, and climate regimes across multiple watersheds and at multiple scales. A database of this nature would benefit scientists and managers concerned with the maintenance and restoration of riparian plant communities. These methods make it possible to gather precise data over greater spatial and temporal extents not practical for field crews. It can significantly reduce the amount of time required to obtain similar results. These techniques are relatively easy to learn, can be performed with a variety of GIS software packages, and require basic computer processing capabilities.

Table 3. Percent cover of individual willow species, shadow, and ground cover for images resampled (degrade), filtered, and classified with an unsupervised or supervised classification technique.

\begin{tabular}{lccccc}
\hline Species & Color degrade & Color unsupervised & Color supervised-seed & Color supervised-polygon & Infrared supervised-polygon \\
\hline Salix geyerianna & 18 & 24 & 24 & 21 & 35 \\
Salix boothii & 35 & 38 & 47 & 14 & 19 \\
Salix lemmonii & 16 & 18 & 8 & 12 & 12 \\
Shadow & 2 & 18 & 6 & 7 & 14 \\
Bare/grass & 27 & 3 & & & 15 \\
\hline
\end{tabular}




\section{LITERATURE CITED}

Brunsfeld, S. J., And F. D. Johnson. 1985. Field guide to the willows of east-central Idaho. Moscow, ID: Forest, Wildlife, and Range Experiment Station, University of Idaho. Bulletin No. 39. $82 \mathrm{p}$.

Congalton, R. G. 1991. A review of assessing the accuracy of classifications of remotely sensed data. Remote Sensing of Environment 37:35-46.

ERDAS Inc. 1997. ERDAS ${ }^{\circledR}$ Field Guide ${ }^{\mathrm{TM}}$, Version 8.3.1. Atlanta, GA: ERDAS, Inc. $655 \mathrm{p}$.

Golden, M., J. Johnson, V. Landrum, J. Powell, V. Varner, and T. Wirth. 1996. Guidelines for the use of digital imagery for vegetation mapping. Washington, DC: USDA Forest Service, Engineering Staff. EM-7140-25. 125 p.

Harris, N. R., S. H. Sharrow, and D. E. Johnson. 1996. Use of low-level remote sensing to understand tree/forage interactions in agroforests. Geocarto International 11:81-92.

Knopf, F. L., and T. R. Stanley. 2002. Avian responses to late-season grazing in a shrub-willow floodplain. Conservation Biology 16:225-231.

KovalCHIK, B. L., AND W. ELmORE. 1992. Effects of cattle grazing systems on willowdominated plant associations in central Oregon. In: Proceedings—symposium on ecology and management of riparian shrub communities. Ogden, UT: USDA Intermountain Research Station. GTR-INT-289. p 111-119.

LillesAnd, T. M., AND R. W. Kiefer. 2000. Remote sensing and image interpretation. 4th ed. New York, NY: John Wiley and Sons. 724 p.

LowELL, K., AND A. JATON. 1999. Spatial accuracy assessment, land information uncertainty in natural resources. Chelsea, MI: Ann Arbor Press. 455 p.

Mansfield, D. H. 2000. Flora of Steens Mountain. Corvallis, OR: Oregon State University Press. $410 \mathrm{p}$.
Martin, M. E., S. D. Newman, J. D. Aber, and R. G. Congalton. 1998. Determining forest species composition using high spectral resolution remote sensing data. Remote Sensing of Environment 65:249-254.

Meyer, P., K. Staenz, and K. I. ITten. 1996. Semi-automated procedures for tree species identification in high spatial resolution data from digitized colour infrared-aerial photography. ISPRS Journal of Photogrammetry and Remote Sensing 51:5-16.

Newsholme, C. 1992. Willows, the genus Salix. Portland, OR: Timber Press. $224 \mathrm{p}$.

Sali, E., And H. Wolfson. 1992. Texture classification in aerial photographs and satellite data. International Journal of Remote Sensing 13:3395-3408.

Schulz, T. T., AND W. C. LEINInGER. 1990. Differences in riparian vegetation structure between grazed areas and exclosures. Journal of Range Management 43:295-299.

Stuckens, J., P. R. Coppin, and M. E. Bauer. 2000. Integrating contextural information with per-pixel classification for improved land cover classification. Remote Sensing of Environment 71:282-296.

TuelleR, P. T. 1996. Near-earth monitoring of range condition and trend. Geocarto International 11:53-62.

Tueller, P. T., P. C. Lent, R. D. Stager, E. A. Jacobson, and K. A. Platou. 1988 Rangeland vegetation changes measured from helicopter borne $35 \mathrm{~mm}$ aerial photography. Photogrammetric Engineering and Remote Sensing 54:609-614.

Warner, W. S., R. W. Graham, and R. E. Read. 1996. Small format aerial photography. Caithness, Scotland, UK: Whittles Publishing. 370 p.

Wulder, M. A., E. F. LeDrew, S. E. Franklin, and M. B. Lavigne. 1998. Aerial image texture information in the estimation of northern deciduous and mixed wood forest leaf area index (LAI). Remote Sensing of Environment 64:64-76. 